\title{
Office for Protection from Research Risks
}

National Cancer Institute

\section{Source}

National Cancer Institute. Office for Protection from Research Risks. NCI Thesaurus. Code C19773.

The Office for Protection from Research Risks (OPRR) is organizationally located in the Office of the Director, NIH. OPRR is charged with interpreting and overseeing implementation of the regulations regarding the Protection of Human Subjects codified at Title 45, Part 46, of the Code of Federal Regulations. Also, OPRR is responsible for providing guidance on ethical issues in biomedical and behavioral research. 